\title{
Abandono de cães na América Latina: revisão de literatura
}

\section{Abandonment of dogs in Latin America: review of literature}

\section{Resumo}

O abandono de animais é frequente e comum em toda América Latina, causando prejuizos nos âmbitos da saúde pública, social, ecológica, econômia e do bem-estar animal. Estão entre as principais causas de abandono animal: os problemas comportamentais dos animais, problemas relacionados à falta de espaço nas moradias, bem como o estilo de vida dos proprietários, a falta de informação sobre as responsabilidades e custos gerados pela guarda de animais. É crescente o número de leis municipais brasileiras relacionadas ao bem-estar animal, devido à pressão de setores da sociedade, mas os animais abandonados, também, são um problema de responsabilidade da própria sociedade. Idealmente, o papel do médico veterinário é o de informar e educar a população sobre o tema. Reduzir o abandono animal é um desafio público e cultural de solução de longo prazo, que necessita do olhar atento de toda a sociedade.

\section{Summary}

The relinquishment of animals is frequent and common throughout all the Latin America, causing losses in the areas of public health, social, ecological, economic and animal welfare. Among the main causes of pet relinquishment are behavioral problems, lack of space in houses, the lifestyle of the owner, lack of information about the owner responsibilities and costs associated with the keeping of animals. The number of laws related to animal welfare has been growing, due to pressure from the civil population but abandoned animals are a problem of responsibility of all the society. The role of the veterinarian is to inform and educate their customers about the topic. Reduce the relinquishment animal is a public challenge with cultural and long-term solution, and needs the closer look of the whole society. 
Ana Julia Silva e Alves ${ }^{1}$

Aline Gil Alves Guilloux ${ }^{1}$

Carolina Ballarini Zetun ${ }^{1}$

Gina Polo²

Guilherme Basseto Braga ${ }^{1}$

Ligia Issberner Panachão²

Oswaldo Santos ${ }^{2}$

Ricardo Augusto Dias ${ }^{3}$
Ana Júlia Silva e Alves

Faculdade de Medicina Veterinária e Zootecnia

da Universidade de São Paulo

Av. Prof. Dr. Orlando Marques de Paiva, 87

05508-270 - Cidade Universitária.

São Paulo/SP - Brasil

\anajulia@vps.fmvz.usp.br

\section{Palavras-chave}

Cães. Abandono. Saúde Pública. Bem-estar animal. América latina.

\section{Keywords}

Dogs. Abandonment. Public health. Animal

welfare. Latin America.

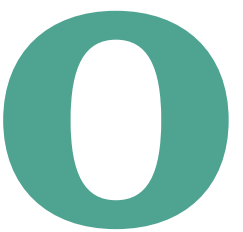

abandono de animais é frequente no Brasil e em toda a América Latina, acarretando uma série de consequências decorrentes da sua presença em locais públicos, sem qualquer tipo de supervisão, restrição e cuidados veterinários. Além disso, o abandono de animais é considerado uma ameaça potencial nas áreas de saúde pública (devido às zoonoses), social (desconforto com relação ao comportamento animal), ecológico (principalmente, no que se refere ao impacto ambiental) e econômico (custos com a estratégia de controle populacional).

Os cães estão envolvidos na história natural de zoonoses como raiva (CEDIEL et. al., 2010), leishmaniose (CRMV-SP, 2010), leptospirose (RODRIGUEZ et. al., 2004), toxocariose (MARTINEZ et. al., 2008) e outras doenças parasitárias (POLO et. al., 2004; MUNDIM et. al., 2007), além das implicações envolvidas com os casos de agressão aos humanos e a outros animais. As mordeduras caninas aumentam o risco de transmissão de zoonoses e são consideradas causa importante de morbidade e mortalidade (MACEDO; ROSA, 2004; CIAMPO et. al., 2000) comprometendo tanto a integridade física como a psicológica das vítimas, especialmente se forem crianças (PALACIO et. al., 2005). Ruídos (latidos e uivos) e excreções (fezes e urina), danos a propriedades públicas e privadas, acidentes de trânsito e manifestação de comportamentos territoriais e sexuais próprios

\footnotetext{
1 Doutorandos do curso de pós graduação em Epidemiologia Experimental Aplicada as Zoonoses da Universidade de São Paulo (FMVZ/USP)

2 Mestrandos do curso de pós graduação em Epidemiologia Experimental Aplicada as Zoonoses da Universidade de São Paulo (FMVZ/USP)

3 Professor da Faculdade de Medicina Veterinária e Zootecnia da Universidade de São Paulo (FMVZ/USP)
} 
da espécie, são outros problemas decorrentes da presença de cães sem supervisão humana (STAFFORD, 2007).

Quanto ao impacto ambiental, os cães de rua são uma fonte de contaminação por meio da eliminação de excreções, além de que quando os animais vêm a óbito, as suas carcaças são frequentemente deixadas em locais impróprios. Além disso, podem ser predadores de animais pertencentes à fauna silvestre com perigo de extinção (GALETTA; SAZIMA, 2006).

As consequências econômicas derivadas da presença de cães de rua estão relacionadas principalmente aos gastos representados por estratégias de manejo populacional. Dessas estratégias, destacam-se a manutenção de centros de controle de zoonoses, programas de esterilização e eutanásia. Nas áreas rurais podem ocorrer também perdas associadas à predação de animais de produção (SLATER, 2001).

Os impactos do abandono no bem-estar animal também são de especial relevância. Apesar da evidência de que o bem-estar dos cães de rua pode ser aceitável em ocasiões (CASTAÑEDA et al, 2001), a situação mais frequente caracteriza-se por condições de saúde física e mental deficientes, agravadas pela maior suscetibilidade a estados de sofrimento e exposição a maus tratos (STAFFORD, 2007).

Entretanto, os cães acolhidos por programas de manejo populacional não estão isentos de condições inaceitáveis de bem-estar, pois se sabe que em centros de controle de animais a qualidade de vida pode estar comprometida (BARRERA et. al., 2008).

\section{DISCUSSÃO}

\section{Fatores relacionados ao abandono de animais}

Há pouca literatura no Brasil e na América Latina relacionando fatores associados ao abandono de animais. A maioria das informações é encontrada em países como Estados Unidos e alguns países asiáticos. Apesar de realidades diferentes da América Latina, o estudo sobre os fatores de risco de abandono nos países acima citados pode ser um primeiro passo para o conhecimento mais profundo da situação latina americana.

Nos Estados Unidos, as causas referidas para entrega de cães em abrigos foram, em primeiro lugar, problemas comportamentais dos animais (46,8\% dos casos) e em segundo lugar, mudanças na disponibilidade de espaço ou nas regras de conduta social do espaço ocupado pelo ser humano $(29,1 \%)$. Ainda como causas importantes de abandono, constam o estilo de vida do proprietário do cão $(25,4 \%)$, a diferença entre a expectativa (sejam elas emocionais, físicas ou sociais) do proprietário, a preparação deste novo dono para a chegada animal e a realidade nos cuidados do cão (14,6\%) (SALMAN et al., 1998). Em Taiwan, dentre os fatores pós-aquisição, aqueles com maior associação ao abandono também foram os problemas comportamentais dos animais. Neste mesmo estudo, foi observada a associação do insucesso na posse com outros fatores, tais como a motivação da posse (aquisição do cão porque achava ele "fofo") ou a falta de conhecimento sobre os animais (acreditar que se deve reproduzir o cão antes de esterilizar) (WENG et al., 2006).

Segundo Salman et al. (1998), o perfil de proprietários que entregaram cães em abrigos nos Estados Unidos foram, em sua maioria: homens, com média de idade de 38,3 anos, que haviam feito a primeira adoção, que tinham criança em casa e que haviam adotado o cão para a criança. Segundo New et al. (2000), pessoas que abandonaram cães têm maior chance de serem homens, antes dos 50 anos e de não terem alcançado nível educacional além do ensino médio. Kidd, Kidd e George (1992) definiram o perfil daqueles que abandonaram animais em um abrigo antes dos seis meses de posse como sendo pessoas em primeira adoção, homens e com crianças em casa.

Nos Estados Unidos, cães com maior risco de serem abandonados foram cães machos, fêmeas não esterilizadas, cães antes dos dois anos de idade, sem raça definida, com tempo de posse inferior a dois anos, adquiridos a baixo ou nenhum custo e que morderam uma pessoa no último mês. Quanto maior a frequência com que os cães sujavam a casa, provocavam estragos ou eram hiperativos ou medrosos também aumentava o risco de abandono (NEW Jr. et al., 2000).

Salman et al. (1998) referiram que, as características mais frequentes em animais abandonados em abrigos são os não esterilizados, adquiridos em abrigo, adquiridos a baixo custo ou custo zero, antes dos três anos de idade, que passavam mais tempo no quintal do que dentro de casa e que tinham problemas comportamentais.

Com relação à idade de adoção, foi evidenciada uma associação entre animais adotados depois dos seis meses e abandono, enquanto Weng et al. (2006) encontrou associação inversa: quanto mais jovem o cão adotado, maior a chance de insucesso na adoção.

Patronek et al. (1996) observam que, os cães com maior risco de abandono foram aqueles obtidos a baixo ou nenhum custo, não esterilizados, acima dos seis meses na aquisição, que passavam a maior parte do dia no quintal e demandavam mais trabalho do que o esperado na aquisição.

Além da idade do cão adotado, entre os fatores préaquisição estudados, Weng et al. (2006) encontraram como forte determinante de abandono que o proprietário do cão tivesse história prévia de abandono de outro cão. 


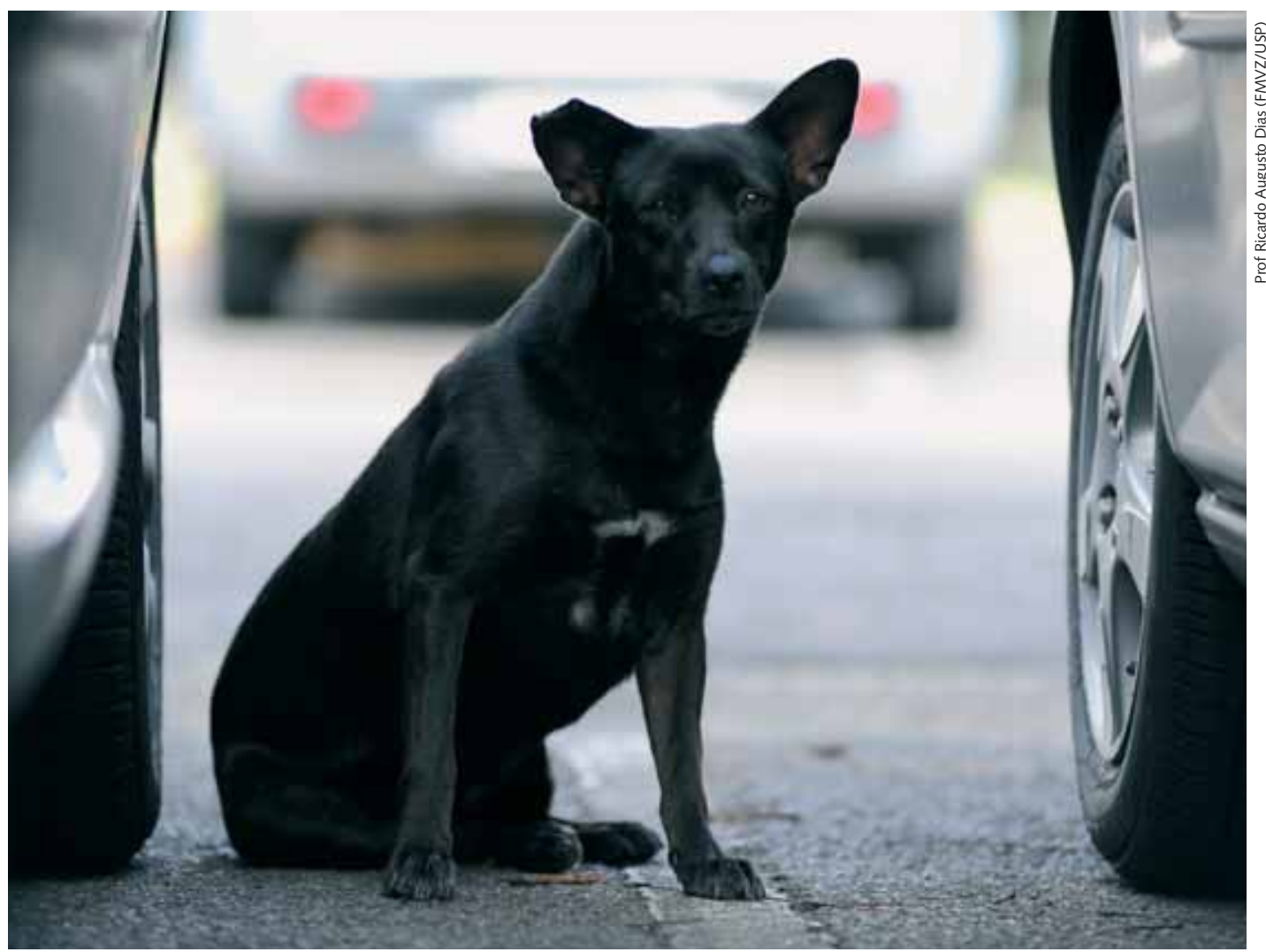

Animal errante do campus da Universidade de São Paulo
Além disto, o tempo médio de posse dos cães abandonados foi de dois anos.

No Brasil, admiti-se que alterações comportamentais podem levar o proprietário a abandonar seus animais e até mesmo optar pela eutanásia (NOVAIS et al, 2010)

\section{Problemas comportamentais}

O interesse científico na etologia canina tem crescido muito nas duas últimas décadas. A expansão do conhecimento nessa área permite a validação das informações transmitidas aos proprietários sobre o manejo de seus animais de estimação. É crucial que os veterinários tenham conhecimento dos comportamentos das espécies com que trabalham para que possam aconselhar os proprietários de forma apropriada (HORWITZ \& MILLS, 2009). Muitas vezes, os distúrbios de comportamento são resolvidos por meio da eutanásia ou do abandono. Os médicos veterinários, independentemente da área que exerçam, mas especialmente o clínico de pequenos animais, pelo seu contato intenso com a população, deve ser um líder na reversão dessa tendência (LANDSBERG et al, 2004).

Ao abordar distúrbios de comportamento, deve-se ter sempre em mente que um animal que se comporta de uma determinada forma pode ser considerado problemático para uma família, porém esse mesmo animal pode ser facilmente tolerado em outro meio social. A tolerância do ser humano em relação aos seus animais depende de suas experiências anteriores, de seu meio cultural e de suas idéias sobre quais comportamentos podem ser considerados adequados. Algumas pessoas não se incomodam que os animais comandem as suas vidas enquanto outras se sentem na obrigação de manter um controle absoluto sobre os mesmos (HORWITZ \& MILLS, 2009).

Os proprietários podem não saber qual é o comportamento canino normal (BEAVER, 2001) ou podem ter expectativas irreais sobre os cães (LANDSBERG et al, 2004; MARDER et al, 2008), pois só conheceram cães individuais como membros de família e não observaram aspectos mais universais do comportamento canino (BEAVER, 2001). Geralmente, os comportamentos considerados problemáticos são os que representam perigo ou geram transtorno no ambiente doméstico. Apesar de serem muitas vezes normais para a espécie, esses comportamentos podem ser socialmente indesejáveis ou até mesmo inaceitáveis (HORWITZ \& MILLS, 2009).

Em alguns casos, pode não ser possível a eliminação dos comportamentos indesejados, até mesmo porque isso seria prejudicial para o bem- estar dos animais, mas ainda assim, é possível modifica-los até que se tornem mais aceitáveis socialmente. Para isso, a família precisa entender porque os animais se comportam de uma 
determinada maneira e aprender como lidar com esses problemas. A prevenção de problemas comportamentais é muito mais fácil, segura e eficiente do que o tratamento de animais que já apresentam distúrbios e deveria ser considerada tão importante quanto o aconselhamento sobre a nutrição dos cães ou sobre os protocolos de vacinação (HORWITZ \& MILLS, 2009).

Evidências preliminares indicaram que a educação e o aconselhamento antes e depois da aquisição de um animal de estimação podem ajudar a reduzir o abandono (LANDSBERG et al, 2004). Quando as pessoas adquirem animais de estimação por razões erradas, não os treinam de maneira adequada ou quando os novos proprietários não estão preparados para as responsabilidades envolvidas, os animais tendem a ser doados para outras famílias ou mandados para instituições (MARDER et al, 2008).

A família que adota um animal deve receber informações sobre os comportamentos considerados normais para a espécie, métodos humanitários de adestramento e estratégias para que o animal apresente, ao longo do tempo, comportamentos adequados ao convívio familiar. É importante que os proprietários saibam que precisam oferecer não só cuidados básicos como uma alimentação adequada, abrigo e atendimento veterinário, mas também as condições para que eles possam interagir socialmente e manifestar os comportamentos próprios da espécie (HORWITZ \& MILLS, 2009).

Os primeiros meses de vida de um animal são os mais importantes para o seu desenvolvimento social (HORWITZ \& MILLS, 2009). O período mais decisivo para a socialização dos cães é entre 3 e 12 semanas de idade. Durante esse período, cães e gatos constroem ligações de forma mais rápida com indivíduos de sua própria espécie, de outras espécies e com novos ambientes. Animais que desenvolvem relações sociais durante esse período são frequentemente capazes de manter essas relações por toda a vida. Se, no final desse período não tiverem sido socializados de maneira adequada com pessoas e outros animais, eles provavelmente se tornarão medrosos, defensivos e potencialmente agressivos quando expostos em uma idade posterior (LANDSBERG et al, 2004).

Cães que, com 14 semanas de idade não têm contato com pessoas, provavelmente não conseguirão se tornar animais de estimação adequados a uma família e tendem a se comportar mais como seus pares selvagens. Deve-se fazer todo tipo de tentativa para introduzir o cão a pessoas, animais e ambientes que ele provavelmente pode encontrar na fase adulta (LANDSBERG et al, 2004).

Essa socialização pode ser obtida na casa da família e/ ou em residências que possuam cães vacinados, saudáveis e pouco expostos a locais onde possam estar facilmente em contato com agentes infecciosos, como parques. A socialização deve ser realizada gradualmente, começando com interações calmas, com poucas pessoas e ao longo do tempo o cão pode ser apresentado a uma maior variedade de pessoas (HORWITZ \& MILLS, 2009).

\section{Legislação}

$\mathrm{Na}$ "Declaração dos Direitos dos Animais", elaborada pela Organização das Nações Unidas para a Educação, a Ciência e a Cultura (UNESCO, 1978), o abandono de animais é considerado "um ato cruel e degradante" e o direito dos mesmos deve ser defendido pela lei como os direitos dos homens e os organismos de proteção e salvaguarda dos animais devem estar representados governamentalmente (UNESCO, 1978).

A maior parte dos países da América Latina possui leis de proteção animal, sendo o abandono de animais classificado como maus tratos por algumas delas como na Colômbia (1989) México (1997) ou como ato cruel e degradante na Nicarágua (2010).

Embora em algumas leis, o abandono não seja considerado como maus tratos, estas vetam aos proprietários ou pessoas encarregadas pelos animais o abandono destes em vias públicas (URUGUAI, 2009; EQUADOR, 2009; PARAGUAI, 1953; VENEZUELA, 2010; PERU, 2000; NICARAGUA, 2010, REPUBLICA DOMINICANA, 2011), rurais (NICARAGUA, 2010) ou em propriedade de particulares (PARAGUAI, 1953; NICARAGUA, 2010).

Nos diferentes países o abandono prevê diferentes sanções, tais como: (a) multas (URUGUAI, 2009; COLOMBIA, 1989; PERU, 2000; MEXICO, 1997; REPUBLICA DOMINICANA, 2011); (b) advertência (MEXICO, 1997, URUGUAI, 2009); (c) prisão (COLOMBIA, 1989; MEXICO, 1997; REPUBLICA DOMINICANA, 2011); (d) suspensão da realização de experimentos (PERU, 2000), e fechamento parcial ou total, temporário ou definitivo, do centro ou instituição geradora da infração (PERU, 2000); (f) apreensão dos objetos, instrumentos ou artefatos utilizados para cometer a infração, no caso de agressão (PERU, 2000); (g) suspensão ou cancelamento da permissão, licença de funcionamento, concessão ou qualquer outra autorização, segundo o caso (URUGUAI, 2009; PERU, 2000); (h) disposição dos animais à autoridade municipal (URUGUAI, 2009; VENEZUELA, 2010); (i) Proibição temporária ou definitiva da posse de animais (URUGUAI, 2009).

Leis de proteção animal em outros países não contemplam o abandono de animais como maus tratos e não o penalizam de nenhuma forma (ARGENTINA, 1954; 


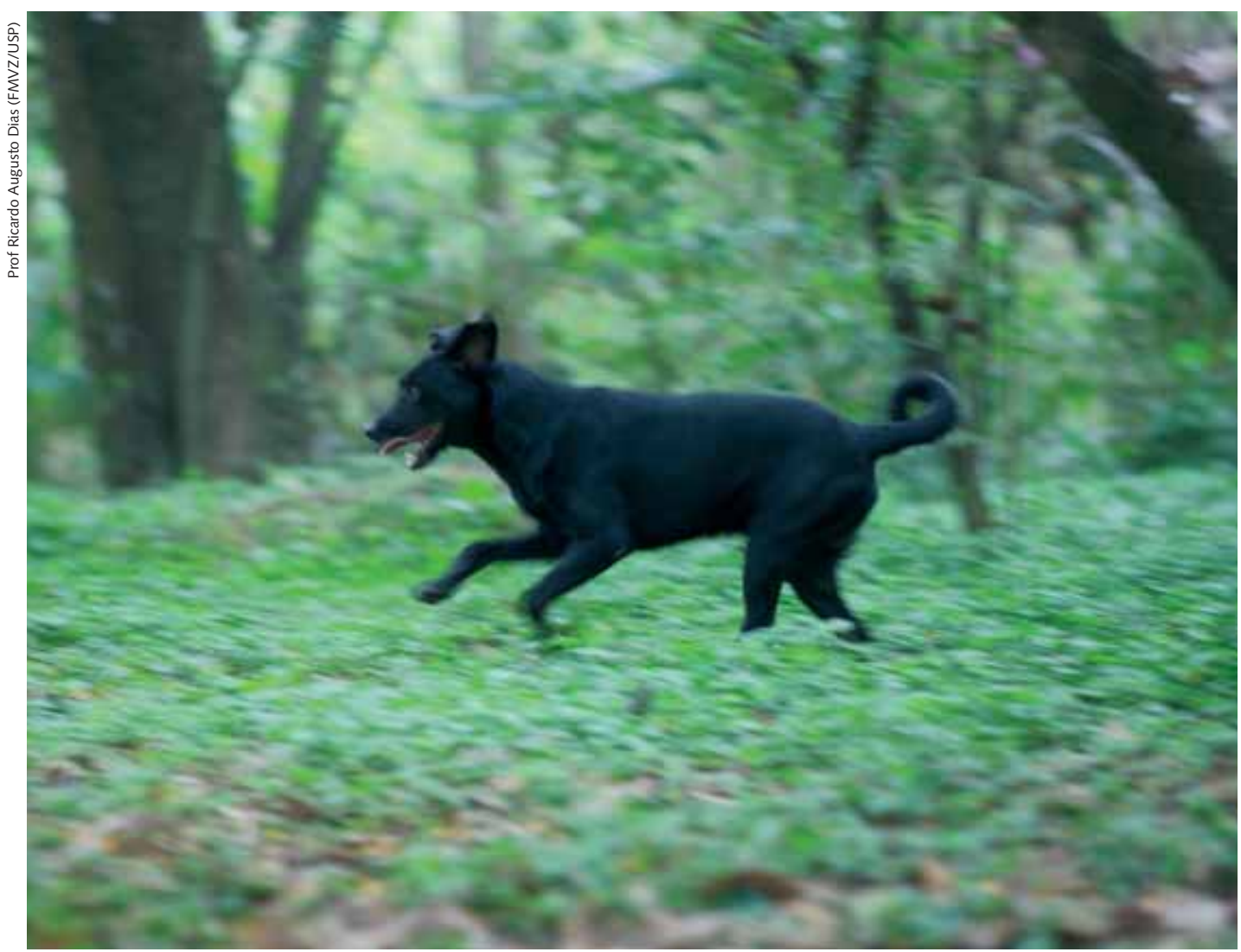

CHILE, 2009; COSTA RICA, 1994). Em países, como Cuba, El Salvador, Guatemala, Haiti e Panamá não foram encontrados leis de proteção animal.

No Brasil, a Lei Federal 9.605 de 1998 (BRASIL, 1998), considera como maus tratos abandonar, espancar, envenenar, não dar comida diariamente, manter preso em corrente, local sujo ou pequeno demais os animais domésticos, entre outras práticas. Esta mesma lei dispõe sobre as sanções penais e administrativas derivadas de condutas e atividades lesivas ao meio ambiente e considera como crime: "Praticar ato de abuso, maus-tratos, ferir ou mutilar animais silvestres, domésticos ou domesticados, nativos ou exóticos", sendo a pena de detenção de três meses a um ano (aumentada em caso de morte do animal) e multa.

No Brasil, o Decreto Federal no 24.645 de 1934 (BRASIL, 1934), define maus tratos como qualquer ação voltada contra os animais que implique em crueldade, especialmente em ausência de alimentação mínima necessária, excesso de peso de carga, tortura, uso de animais feridos e submissão a experiências pseudocientíficas.

Na cidade de São Paulo, a Lei Municipal no 10.309 de 1987 que dispõe sobre controle de população e controle de zoonoses no Município estipula que é proibido abandonar animais em qualquer área pública ou privada, indicando que os animais não mais desejados por seus proprietários serão encaminhados ao Órgão Sanitário responsável (SÃO PAULO, 1987). Adicionalmente, é proibida a permanência de animais soltos nas vias e logradouros públicos ou locais de livre acesso ao público, que será apreendido todo e qualquer animal encontrado solto nas vias e logradouros públicos ou locais de livre acesso ao público e que os animais apreendidos poderão sofrer as seguintes como destinações: resgate, leilão, adoção, doação ou eutanásia (São Paulo, 1987).

No ano 2001, esta lei foi modificada pela Lei Municipal $n^{\circ} 13.131$ que estabelece, no artigo $23^{\circ}$ que é proibido soltar ou abandonar animais em vias e logradouros públicos e privados e os proprietários só poderão encaminhar seus animais ao órgão municipal responsável pelo controle de zoonoses para destinação em casos de enfermidades ou agressões comprovadas. Considera como maus-tratos o abandono de cães e gatos em vias públicas ou logradouros públicos (SÃO PAULO, 2001), estabelecido que o órgão municipal responsável pelo controle de zoonoses deverá promover um programa de educação continuada de conscientização da população a respeito da propriedade de guarda de animais domésticos, podendo para tanto, contar com parcerias e entidades de proteção animal e outras organizações não governamentais e governamentais, universidades, empresas públicas e/ou privadas (nacionais ou internacionais) e entidades de classe ligadas aos médicos 
veterinários (SÃO PAULO, 2001). Porém a prevenção do abandono não está estipulada dentro do material do programa de educação continuada.

No ano 2008 foi aprovada a lei ${ }^{\circ} 12.916$ que estabelece que para ser efetiva a educação para a propriedade guarda responsável, o Poder Público poderá viabilizar as campanhas que conscientizem o público de que o abandono, pelo padecimento infligido ao animal, configura, em tese, prática de crime ambiental (São Paulo, 2008).

Cumpre ser destacado que os cidadãos brasileiros têm o direito de participar diretamente da elaboração de leis por meio de projetos de iniciativa popular, plebiscitos e referendos (ANDRADE, 2003).

\section{Procedimento para denúncia de abandono}

No Brasil, de acordo com Lei Federal 9.605 de 1998, é considerado crime maus tratos de animais (incluindo o abandono de animais) e deve ser denunciado .

\section{CONCLUSÃO}

O abandono de animais é frequente no cotidiano do Médico Veterinário. Animais são eventualmente abandonados nas portas de clinicas veterinárias e com frequência, o clínico, atende animais resgatados e estimula a sua doação. A questão principal é: qual é o papel do médico veterinário frente ao problema de abandono de animais e à presença de animais errantes. Esta reflexão nos remete à conclusão de que o problema não é apenas desse profissional, mas sim de toda a sociedade.

O papel deste profissional é o de informar e de educar a população a respeito da guarda de animais. Quem adota um animal, deve ser orientado sobre a responsabilidade associada a sua aquisição, já que o animal terá um período longo de vida e, sendo assim, vai requerer cuidados básicos custosos em longo prazo. Os médicos veterinários podem e devem promover a guarda responsável e informar a respeito da prevenção das zoonoses.

Alterações comportamentais como já citadas anteriormente são as principais causas de abandono. Em algumas faculdades de Medicina Veterinária, esse tema é pouco abordado e deve-se refletir sobre o fato de que o conhecimento nesta área pode minimizar os efeitos comportamentais não desejáveis (os que são passíveis de modificações) e com isso, diminuir eventuais abandonos por este motivo.

Os Centros de Controle de Zoonoses (CCZ) são instituições promotoras de Saúde Pública que têm como atribuições prevenir e controlar as zoonoses. Estas instituições devem ser valorizadas, uma vez que a elas foi atribuída toda a responsabilidade do manejo de cães abandonados, um problema majoritariamente criado pela própria sociedade. Ao mesmo tempo, depositar toda a responsabilidade nos Centros de Controle de Zoonoses não é a melhor saída, dada a sua capacidade operacional e logística limitada.

A saída pode ser a interação do serviço público com os médicos veterinários privados intensificando as ações de controle da população de animais abandonados no país, parceria com Universidades e por meio uma melhor estruturação operacional, com recursos tecnológicos para o controle populacional e prevenção de zoonoses.

O desafio de evitar o abandono e solucionar as situações dos animais já abandonados é imenso. É um desafio público e cultural, e certamente com resolução possível, porém em longo prazo.

\section{Referências}

ARGENTINA. Ley Nacional 14.346 de Protección Animal. Sancionada no Congresso Nacional 27 de setembro de 1954. Disponível em: <http://www.alihuen.org.ar/ legislacion-ambiental/ley-nacional-14.346-de-proteccion-animal.html>. Acesso em: 13 de março de 2012

ANDRADE, A. M. A participação da sociedade civil no processo legislativo: A contribuição da comissão de legislação participativa da câmara dos deputados. Dísponivel em <http:// bd.camara.gov.br>. Acessado em 23 de julho de 2012

BARRERA, G.; JAKOVCEVIC, A.; BENTOSELA, M. Calidad de Vida en Perros Alojados en Refugios: Intervenciones para Mejorar su Bienestar. Suma Psicológica. v. 15, p. 337354. 2008.

BEAVER B. V. Comportamento Canino: um guia para veterinários. São Paulo: Roca, 2001.

BRASIL. Lei Federal no 9.605, de 12 de fevereiro de 1998. Dispõe sobre as sanções penais e administrativas derivadas de condutas e atividades lesivas ao Meio Ambiente, e dá outras providências. Disponível em: <https://www.planalto.gov.br/ccivil_03/leis/ 19605.htm>. Acesso em 13 de março de 2012.

BRASIL. Decreto Federal n 924.645, de 10 de julho de 1934. Estabelece medidas de proteção aos animais. Disponível em: <http://www.planalto.gov.br/ccivil_03/ decreto/1930-1949/D24645.htm>. Acesso em 13 de março de 2012.

CASTAÑEDA, H.; CASTELLANOS A; CALDERÓN, N. Evaluación del comportamiento social de un grupo de individuos de la población canina callejera en la Gaitana localidad de Suba. 2002. Trabalho de conclusão de curso (graduação). Universidad Distrital Francisco Jose de Caldas Facultad de Ciencias y Educación

CEDIEL N.; HOZ, F.; VILLAMIL, L.C.; ROMERO J.; DIAZ, A. Epidemiología de la rabia canina en Colombia. Rev. salud pública. v. 12, p. 368-379. 2010.

CIAMPO, L.A.; RICCO, R.G.; ALMEIDA, C.A.; BONILHA, L.R.; SANTOS, T.C. Acidentes de mordeduras de cães na infância. Revista de Saúde Pública. v. 34, p. 411-412. 2000. CHILE. Ley 20.380 sobre Protección de Animales de 25 de Agosto de 2009. Disponível em: <http://www.leychile.cl/Navegar?idNorma=1006858>. Acesso em: 13 de março de 2012.

COLOMBIA. Ley 84 de 1989. Estatuto Nacional de Protección Animal. Por la cual se adopta el Estatuto Nacional de Protección de los Animales y se crean unas contravenciones y se regula lo referente a su procedimiento y competência. Disponível em : <http://www. alcaldiabogota.gov.co>. Acesso em 13 de março de 2012. 
COSTA RICA. Ley no 7451 do 13 de dezembro de 1994. Ley de bienestar de los animales. La Gaceta no 236 do 13 de dezembro de 1994. Disponível em: <www.poderjudicial.go.cr >. Acesso em: 13 de março de 2012.

CRMV-SP. Conselho Regional de Medicina Veterinária do Estado de São Paulo. Informativo do Conselho Regional de Medicina Veterinária do Estado de São Paulo. v. 42. 2010. EQUADOR. Reglamento Nacional de Tenencia y Manejo Responsable de Perros. 2009 Disponível em: <http://www.pae.ec/legislacion/legislacion-vigente/263-reglamentonacional-de-tenencia-de-perros.html>. Acesso em: 13 de março de 2012

GALETI, M.; SAZIMA, I. Impacto de cães ferais em um fragmento urbano de Floresta Atlântica no sudeste do Brasil. Natureza e Conservação. v. 4, p. 58-63. 2006.

LANDSBERG, G.; HUNTHAUSEN W.; ACKERMAN L. Problemas comportamentais do cão e do gato. São Paulo: Roca, 2004.

HORWITZ D.F.; MILLS D. S.; BSAVA. Manual of Behavioural Medicine. Second Edition Gloucester, British Small Animal Veterinary Association, England 2009.

KIDD, A. H.; KIDD, R. M.; GEORGE, C. C. Successful and unsuccessful pet adoptions. Psychological Reports, v. 70, p. 547-561, 1992

MARDER, A.; DUXBURY M.M. Obtaining a Pet: Realistic Expectations. Veterinary Clinics Small Animal Practice 38, 1145-1162, 2008.

MACEDO, J.L; ROSA, S.C.; Reconstrução de couro cabeludo após mordedura canina. Rev. Col. Bras. Cir. v. 31, p. 27-33. 2004.

MARTINEZ, I.; GUTIERREZ, M.; RUIZ, L.A.; GUTIERREZ, E.M.; SOSA, A.A.; VALENCIA J.L.; GAONA, E. Prevalence of anti-T. canis antibodies in stray dogs in Mexico City. Veterinary Parasitology. v. 153, p. 270-276. 2008

MEXICO. Ley 5 de 24 de abril de 1997. Protección de los Animales de Compañia Disponível em: <http://noticias.juridicas.com/base_datos/CCAA/cl-15-1997.html> Acesso em 13 de março de 2012.

MUNDIM, M.J.S.; ROSA, L.A.G.; HORTÊNCIO, S.M.; FARIA, E.S.M.; RODRIGUES R.M.; CURY, M.C. Prevalence of Giardia duodenalis and Cryptosporidium spp. In dogs from different living conditions in Uberlândia, Brazil. Veterinary Parasitology. v. 144. p. 356-359. 2007

NEW Jr., J. C.; SALMAN, M. D.; KING, M.; SCARLETT, J. M.; KASS, P. H.; HUTCHISON J. M. Characteristic of Shelter-Relinquished Animals and Their Owners Compared With Animals And Their Owners in U.S. Pet-Owning Households. Journal of Applied Animal Welfare Science, v. 3, n. 3, p. 179-201, 2000

NICARAGUA. Ley de 5 de 02 de dezembro de 2010. Ley para la protección y bienestar de los animales domésticos y animales silvestres domésticos. Disponível em: <http:// legislacion.asamblea.gob.ni/Diariodebate.nsf/1e91f0054ac77a85062572e50067fde4/6d6 7b54c23a07fc50625784000554742? OpenDocument>. Acesso em 13 de março de 2012.

NOVAIS, A.A.; LEMOS, D. S. A.; JUNIOR, D. F. Síndrome da Ansiedade de Separação em cães atendidos no Hospital Veterinário da Unicastelo. Ciência Animal Brasileira. v. 11. $n$ ○1. Fernandópolis.

PALACIO, J.; LEÓN, M.; GARCIA, S. Aspectos epidemiológicos de las mordeduras caninas. Gac Sanit. v. 19, p. 50-58. 2005.

PARAGUAI. Ley no 67 de 2 de março de 1953. Por el cual se reprime los actos de crueldad contra los animales, asi como los conducentes a la destruccion inmotivada de las plantas. Disponível em: <www.glin.gov>. Acesso em: 13 de março de 2012.

PATRONEK, G. J.; GLICMAN, L. T.; BECK, A. M.; MCCABE, G. P. ECKER, C. Risk factors for relinquishment of dogs to an animal shelter. Journal of the American Veterinary Medical Association, v. 209, p. 572-581, 1996.

PERU. Ley Peruana de Proteccion a los Animales Domesticos y a los Animales Silvestres Mantenidos en Cautiverio n 27.265 de 8 de maio de 2000. Disponível em: <http://
www.orca.org.pe/Ecosonar/articulosespeciales_Ley4248PBA.htm>. Aceso em: 13 de março de 2012

POLO, L.J.; CORTÉS, J.A.; VILLAMIL, L.C.; PRIETO, E. Contaminación de los Parques Públicos de la Localidad de Suba, Bogotá con Nemátodos Zoonóticos. Rev. salud pública. v. 9 , p. 550-557, 2007.

REPUBLICA DOMINICANA. Ley n 1.268 de 19 de outubro de 1946. Ley de protección animal Disponível em: <http://www.camaradediputados.gov.do/masterlex/mlx/ docs/24/106/107/12B8/12DO.htm>. Acesso em: 13 de março de 2012.

RODRÍGUEZ, A.L.; FERRO, B.E; VARONA, M.X.; SANTAFÉ, M. Leptospirosis en perros callejeros de Cali. Biomédica. v. 24, p. 291-295. 2004.

SALMAN, M. D.; NEW Jr., J. G.; SCARLETT, J. M.; KASS, P. H.; RUCH-GALLIE, R.; HETTS, S. Human and Animal Factors related to the relinquishment of Dogs and Cats in 12 Selected Animal Shelters in the United States. Journal of Applied Animal Welfare Science, v. 1, n. 3, 206-226, 1998.

SÃO PAULO. Lei Municipal no 10.309, de 22 de abril de 1987. Dispõe sobre controle de população e controle de zoonoses no Município de São Paulo, e dá outras providências. Disponível em: <http:// www.prefeitura.sp.gov.br> Acesso em 13 de março de 2012.

SÃO PAULO. Lei Municipal no 13.131, de 18 de maio de 2001. Disponível em: <http:// www.prefeitura.sp.gov.br>. Acesso em 13 de março de 2012.

SÃO PAULO. Lei no 12.916, de 16 de abril de 2008. Dispõe sobre o controle da reprodução de cães e gatos e dá providências correlatas. Disponível em: http://www. al.sp.gov.br. Acesso em: 13 de março de 2012.

SLATER, M.R. The role of veterinary epidemiology in the study of free-roaming dogs and cats. Preventive Veterinary Medicine, v. 48, p. 273-286. 2001.

STAFFORD, K. The Welfare of Dogs. The Netherlands. Springer. 2007.

UNESCO. Declaração dos direitos dos animais, de 27 de janeiro de 1978. Disponível em: http://www.forumnacional.com.br/declaracao_universal_dos_direitos_dos_animais.pdf. Acesso em: 13 de março de 2012.

URUGUAI. Ley $\mathrm{n}^{\circ} 18.471$ de Tenencia Responsable de Animales del 27 de março de 2009. Díctanse normas relacionadas con el bienestar animal. Disponível em: <http://200.40.229.134/leyes/AccesoTextoLey.asp?Ley=18471\&Anchor>. Acesso em: 13 de março de 2012.

VENEZUELA. Ley para la protección de la fauna doméstica libre y encautiverio no 39.338 do 4 de janeiro de 2010. Gaceta oficial de la República Bolivariana de Venezuela. Disponível em: <http://issuu.com/noticierolegal/docs/39338>. Aceso em: 13 de março de 2012.

WENG, H. Y.; KASS, P. H.; HART, L. A.; CHOMEL, B. B., Risk factors for unsuccessful dog ownership: An epidemiologic study in Taiwan. Preventive Veterinary Medicine, v. 77, p. 82-85, 2006 